\title{
A la memoria de Jorge Antonio Tapia Valdés
}

Han transcurrido más de dos décadas desde que el Dr. Jorge Tapia Valdés comenzó a conversarnos sobre la importancia de la paradiplomacia en las relaciones bilaterales y multilaterales de Chile con sus vecinos y otras naciones del continente, incluso allende el océano Pacífico, aunque su preocupación preferente era Bolivia. Compartió en esos años, entre 1998 y 2010, cuando estuvo trabajando en estas tierras nortinas, el interés por Bolivia con Carlos Martínez Sotomayor, quien había sido "el Canciller del Lauca”, un litigio que inició Bolivia sobre las aguas de ese río internacional y que concluyó con la ruptura de relaciones diplomáticas. Martínez Sotomayor era ferviente partidario de los corredores que permitirían exportar la soya brasileña por los puertos del Pacífico, peruanos y chilenos, pasando generosamente por Bolivia. Jorge Tapia compartía esa perspectiva, a la que le sumaba su confianza en la paradiplomacia que podría surgir entre las regiones contiguas de los países con el propósito de un desarrollo compartido. Aquí supo de esa histórica relación simbiótica entre Oruro y Tarapacá.

Nadie entonces imaginaba que Bolivia pudiera llevar a Chile a la CIJ de La Haya, y menos que sería durante el gobierno del primer Presidente indígena, Evo Morales Ayma. Jorge conocía muy bien dicha corte, debido a su larga estadía en Holanda.

El libro "La mediterraneidad de Bolivia y el factor peruano", escrito junto a Luciano Mardones Cappanera, publicado por la Editorial Jurídica en Santiago de Chile, en 2011, es la obra que expresa con más detalle su perspectiva. Quizás sea un buen momento de volver a leerla.

Jorge Tapia era un convencido que la diplomacia debería dejar de mirar — aunque fuera brevemente - el horizonte de los grandes acontecimientos, y enfocarse en aquellos aparentemente pequeños, regionales, para encontrar las claves para la resolución de los problemas actuales y para la prospección de escenarios del porvenir.Algunos de esos acontecimientos — aparentemente menores - caben en lo que algunos especialistas denominan "paradiplomacia”, un campo de estudio que Jorge dominó con maestría e introdujo en la discusión académica chilena.

Jorge Tapia tuvo particular dominio de muchos temas relevantes, especialmente en el campo jurídico y sociopolítico. Sus libros y artículos seguirán consultándose, especialmente en estos momentos en un Chile que se abre a una nueva constitución y a una descentralización efectiva. Jorge políticamente era un socialdemócrata que atesoraba esos valores que caracterizaron a lo mejor del Partido Radical chileno, aquel de Pedro Aguirre Cerda. 
Max Weber nos habla de la vocación del político y el científico. Jorge Tapia poseía esa doble vocación y las desarrolló con pasión y profundidad. Llegó a los más altos cargos que permite la política: ministro de Estado, embajador, intendente. Y a las categorías académicas más relevantes: doctor, profesor, investigador, director de institutos, decano. Hubiese sido un excelente rector.

La vocación hacia la política y hacia la ciencia, en algunos casos, podría compararse con el "don" - como en los pueblos antiguos - que se transmite como un regalo de una generación a otra. Derrida dice precisamente que el "don" requiere tiempo. Pienso que Jorge Tapia traspasó dones a las siguientes generaciones: a sus alumnos, discípulos, colegas más jóvenes, etc. Luego ellos harán lo mismo.

Una antigua mitología chipaya dice que cuando un indígena fallece y es enterrado en alguna de sus comunidades, al borde del salar de Coipasa, en el occidente de Bolivia, su alma viaja a Tarapacá donde emergerá. Ellos dicen "se fue para Tarapacá" como una forma de decir que partió para siempre. En la costa de Tarapacá todavía algunos lugares cuyos nombres, topónimos, sugieren un origen uru-chipaya o puquina, según el connotado lingüista peruano Rodolfo Cerrón Palominos. Todavía — en este siglo xxI - esos viajantes milenarios transitan por los Andes para llegar a la costa del Pacífico, porque así lo dicta su cosmovisión. Cuando visitamos a Jorge Tapia en Madrid, en octubre de 2018, recordaba con emoción a Iquique (dos gatos iquiqueños le acompañaban). Le dijimos que su nombre tampoco había sido olvidado en el heroico puerto mayor. Mutatis mutandis, Jorge merece que digamos “se fue para Tarapacá", porque en la arena de Cavancha quedaron sus huellas grabadas para siempre.

Sergio González Miranda

Premio Nacional de Historia 2014

Universidad de Tarapacá

Caleta Molle

En víspera de La Tirana 2020 
